was a good classical scholar, and could converse with perfect fluency in English, French, German, Danish, and Italian; and could read with ease nearly all the modern European languages. He made some strong friendships among his colleagues, and his acknowledged ability and his manner and address, which were eminently those of a polished gentleman and man of the world, won for him universal respect and esteem.

Altogether I looked upon Rudolf von WillemoesSuhm as a young man of the very highest promise, perfectly certain, had he lived, to have achieved a distinguished position in his profession, and I look upon his untimely death as a serious loss not only to the expedition in which he took so important a part, but also to the younger generation of scientific men among whom he was steadily preparing himself to become a leader.

H.M.S. Challenger, Tahiti, Oct. I

$$
\text { C. WYVILLE THOMSON }
$$

\section{THE PENIKESE SCHOOL}

$\mathrm{R}$ readers will regret to hear that the Anderson School of Natural History in Penikese Island, U.S., has come to an untimely end, and will no doubt regret still more that it has done so amid much unpleasant feeling between those chiefly concerned. We shall endeavour to state fairly the facts of the case.

$\mathrm{Mr}$. Anderson, who is a wealthy merchant, made a gift of Penikese Island and 50,000 dollars in cash to the late Prof. Agassiz, in order to enable him to start a school for the practical teaching of natural history. This sum, it may well be believed, was only sufficient to start the school, erect buildings, furnish apparatus, and other necessaries. No one can complain that Mr. Anderson did not also endow the school, and during the life-time of the elcler Agassiz there seems to have been no difficulty as to funds. On his death, his son, Mr. Alexander Agassiz, undertook to carry on the school. This he did, we believe, very unwillingly, as he knew there were no funds available for the daily business of the school, and he did not consider the island a suitable location for such an institution unless largely endowed. Moreover, it was his father's earnest wish that he should devote mosi of his time and energy to the Museum at Cambridge. However, he consented to conduct the school on condition that Mr. Anderson wculd contribute the sum of 10,000 dollars towards its support for the next three years. The first intimation of any dissatisfaction on the generous donor's part seems to have been made to the trustees at the end of 1874 , when he sent them $1329^{6} 60$ dollars to pay off debts which had been incurred, announcing at the same time that this was the last contribution he would make. The trustees seem, nevertheless, to have made every effort to carry on the school. A member of Prof. Agassiz's family contributed a guarantee fund of 3,000 dollars, and appeals were made in all directions, but without anything like success. Clearly the trustees and the teachers themselves could not be expected to carry on the school at their own expense, and all that they had any right to look for from Mr. Anderson was the balance of the 10,000 dollars which he promised; why he failed to contribute this, we are unable to say. Had he done so, those interested in the success of the school would have had time to set about raising something like an endowment fund, and a fine opportunity would have been afforded to the U.S. Government to show their appreciation of practical scientific teachers and scientific research. As it was, the only course which seemed left to the trustees, when everything is taken into account, was to close the school and sell off the furniture and aquaria. Mr. Anderson seems to have considered himself ill used and insulted by the trustees, and Mr. Agassiz in particular; but so far as the facts are known to us, we certainly believe he is mistaken. Mr. Agassiz has duties of the highest importance to attend to in connection with the Cambridge Museum, and he could not possibly be expected to waste his time and energy on an undertaking in whose success no one seemed to be interested. He seems to us to have acted in a straightforward and honourable manner, and only to have given up the school when he saw there was no possible hope of getting funds to carry it on. Mr. Anderson, for some reason which does not appear, seems to have lost his temper, and may naturally have been annoyed that the public did not come forward in support of the school which he so generously founded. The result is certainly to be regretted, but we hope that Mr. Agassiz and Mr. Anderson may come to a better understanding, and that even if the school be not again started, the latter will see that the former has acted all along in the interests of science, whose servant he is. To have touched the Agassiz Memorial Fund, now 347,000 dollars, as some one sug gested should have been done, was simply impossible; it was collected for a special purpose.

Mr. Agassiz took two of the most promising Penikese pupils into his laboratory at Newport, and intends, we believe, as soon as the necessary means can be collected, to establish a school at some more suitable locality.

\section{THE THEORYOF"STREAM LINES" INRELA.} TION TO THE RESISTANCE OF SHIPS *

\section{II.}

I T might at first sight appear that I have now the materials for the proof of my chief proposition, the assertion of the unresisted progress of a submexgerl body ; for such a body might be assumed to be surrounded by a system of imaginary pipes, as shown in Fig. 8; and each of these pipes heing in equilibrium

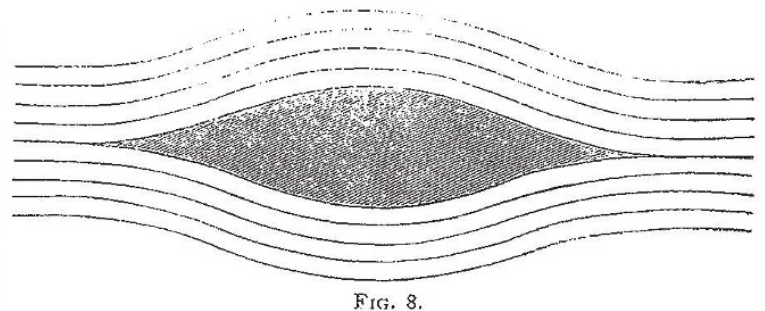

endways, that is to say, the flow of fluid through it not tending in the aggregate to move it end ways, neither, it might be said, would the fow of fluid tend to move the submerged body endways. But this reasoning would not be sound. The pipes we have hitherto been considering have been of uniform sectional area throughout their length, an assumption which has been necessary to the treatment pursued, as the velocity has in each case been assumed to be uniform throughout the pipe. The section of the pipe may have been square, circular, trapezoidal, or any other form; but the area of the section has been assumed to be the same throughout the length of the pipe.

But pipes of uniform sectional area do not truly represent the flow of a fluid past a submerged body. I shall presently ask you to consider the fluid as flowing past the body through a system of imaginary pipes; but to render the assumption admissible, the sides of the imaginary pipes must not be so placed as to interfere with the established course of the fluid, whatever that may be ; in other words, if, for the sake of illustrating the behaviour of the fluid, we assume that it is divided into streams or filaments flowing through imaginary pipes, we must accept such a form for those imaginary pipes that their sides exactly follow the paths of the adjacent particles of fluid.

Now such a rule may, and probably will, require the imaginary pipes to be of varying sectional area throughout their length. Therefore, before we can apply the analogy of the flow of fiuid through pipes to the flow of a fluid past a submerged body, it is necessary to consider the behaviour of fluid in pipes of varying sectional area.

It is, I think, a very common but erroneous impression, that a * Address to the Mechanical Section of the British Association, Bristol, August $25, x 875$; by William Froude, C.E., M.A., F.R.S. President the Section. Revised and extended by the author. Continued from p. $5^{2}$. 
fluid in a pipe exercises, in the case of its meeting a contraction (see Fig. 9), an excess of pressure against the entire converging surface which it meets, and that, conversely, as it enters an enlargement(see Fig. Io), a relief of pressure is experienced by the entire

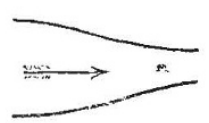

FIG. 9 .

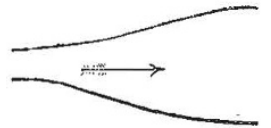

Fig. 10. diverging surface of the pipe. Further, it is commonly assumed that, when passing through a contraction (see Fig. II), there is

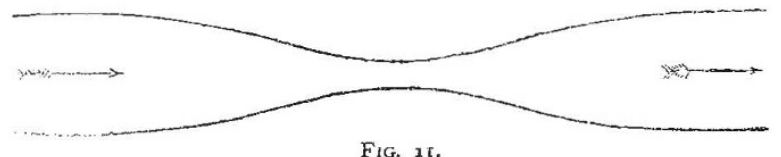

in the narrow neck an excess of pressure due to the squeezing together of the fluid at that point.

These impressions are in no respect correct; the pressure at the smallest part of the pipe is, in fact, less than that at any other point, and vice versâ.

If a fluid be flowing along a pipe which has a contraction in it (see Fig. I2), the forward velocity of the fluid at $B$ must be

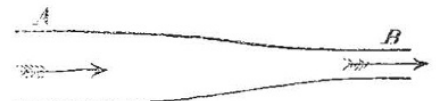

F1G. I2.

greater than that at $A$, in the proportion in which the sectional area of the pipe at $B$ is less than that at $A$; and therefore while passing from $A$ to $B$ the forward velocity of the fluid is being increased. This increase of velocity implies the existence of a force acting in the direction of the motion; that is to say, each particle which is receiving an increase of forward velocity must have a greater fluid pressure behind it than in front of it; for no other condition will cause that increase of forward velocity. Hence a particle of fluid, at each stage of its progress along the tapering contraction, is passing from a region of higher pressure to a region of lower pressure, so that there must be a greater pressure in the larger part of the pipe than in the smaller, and a diminution of pressure at each point corresponding with the diminution of sectional area ; and this difference of pressure must be such as to supply the force necessary to establish the additional forward velocity required at each point of the passage of the fluid through the contraction. Consequently, differences of pressure at different points in the pipe depend simply upon the velocities at those points, or, in other words, on the relative sectional areas of the pipe at those points. *

It is simple to apply the same line of reasoning to the converse case of an enlargement. Here the velocity of the particles is being reduced through precisely the same series of changes, but in an opposite order. The fluid in the larger part of the pipe moves more slowly than that in the smaller, so that, as it ad. vances into the enlargement, its forward velocity is being checked; and this check implies the existence of a force acting in a direction opposite to the motion of the fluid, and each particle being thus retarded must therefore have a greater fluid pressure in front of it than behind it; thus a particle of fluid at each stage of its progress along a tapering enlargement of a pipe is passing from a region of lower pressure to a region of higher pressure. As is well known, the force required to produce a given change of velocity is the same, whether the change be an increase or a decrease. Hence, in the case of an enlargement of a pipe, as in the case of a contraction, the changes of velocity can be satisfied only by changes of pressure, and the law for such change of pressure will be the same, mutatis mutandis.

In a pipe in which there is a contraction and a subsequent enlargement to the same diameter as before (see Fig. II), since the differences of pressure at different points depend on the differences of sectional area at those points, by a law which is exactly the same in an "enlarging as in a contracting pipe, any points which have the same sectional area will have the same pressures,

$$
\text { * See Supplementary Note B. }
$$

the pressures at the larger areas being larger, and those at the smaller areas smaller.

Precisely the same result will follow in the case of an enlargement followed by a contraction (see Fig. 13).*

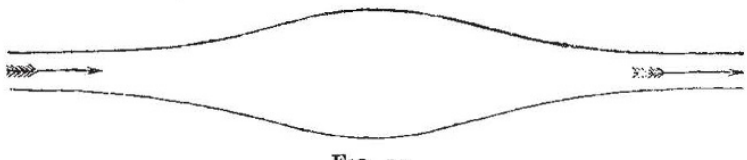

FIG. $x_{3}$.

This proposition can! be illustrated by experiments performed with water.

Figs. 14, 15 show certain pipes, the one a contraction followed by an enlargement, and the other an enlargement followed by

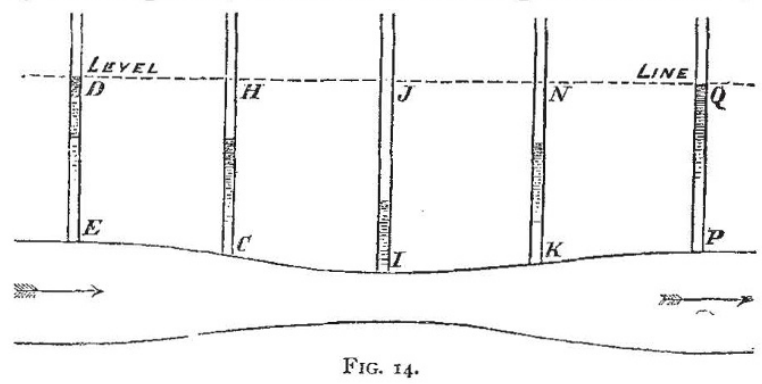

a contraction. At certain points in each pipe, vertical gauge. glasses are connected, the water-levels in which severally indicate the pressures in the pipe at the points of attachment.

In Fig. 14 the sectional areas at $\mathrm{P}$ and $\mathrm{E}$ are equal to one another. Those at $\mathrm{C}$ and $\mathrm{K}$ are likewise equal to one another, but are smaller than those at $P$ and $E$. The area at $I$ is the smallest of all. Now, if the water were a perfect fluid, the pressures $\mathrm{P} Q$ and $\mathrm{ED}$ would be equal, and would be greater

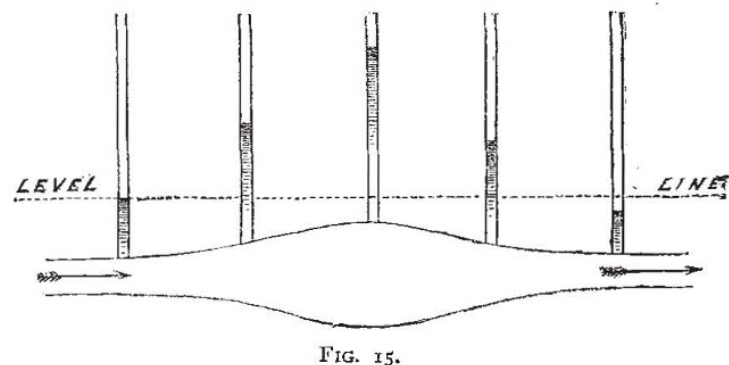

than $\mathrm{CH}$ and $\mathrm{KN} . \mathrm{CH}$ and $\mathrm{KN}$ would also be equal to one another, and would be themselves greater than I $J$.

The results shown in Fig. 15 are similar in kind, equal pres. sures corresponding to equal sectional areas.

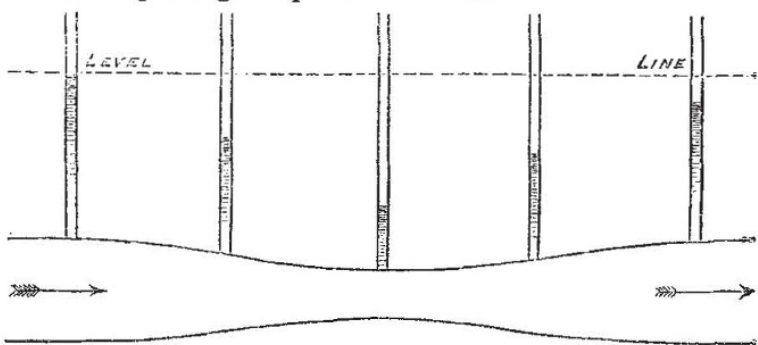

FIG. $x 6$.

As water is not a perfect fluid, some of the pressure at each successive point is lost in friction, and this growing defect in pressure is indicated in the successive gauge-glasses in the manner shown in Figs. 16,17 .

* In a perfect fluid, we may say in a sense, the vis ziva of each particle remains constant. If the particle is stationary, the vis viva is entirely represented by the If the particle is stationary, the vis viva is entirely represented by the pressure; if it be under no pressure, the vis viva is entirely the vis viva is partly represented by the pressure and partly by the velocity. 
As the pressure of the perfect fluid in the pipe at any point depends upon the sectional area at that point, it follows that the amounts of the pressures are independent of the distance, as

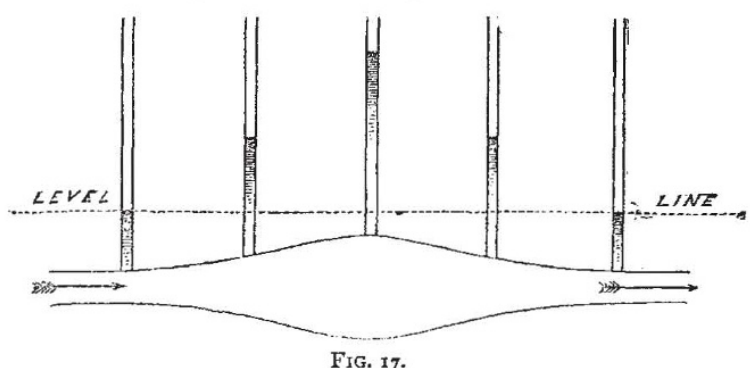

measured along the pipe, in which the area of the pipe alters; so that if in the pipe shown in Fig. 18 the areas at all the points marked $\mathbf{A}$ are equal, if also the areas at all the points marked $\mathbf{B}$ are equal, and so also with those at $\mathrm{C}$ and $\mathrm{D}$, then the pressures at all the points $\mathrm{A}$ will be the same, the pressures at all the points $B$ will be the same, and so with those at $C$ and $D$.

Since, then, the pressure at each point depends on the sectional area at the point and on that only, it is easy to see that the variations in pressure due to the flow are not such as can cause any total endways force on the pipe, provided its sectional area at each end is the same.

Take the pipe shown in Fig. 19. The conical portion of pipe A B presents the same area of surface effective for endways pressure as does the conical portion HI, only in opposite directions. They are both subject to the same pressure, being that appropriate to their effective mean diameter $J$. Consequently the endways pressures on these portions are equal and opposite and neutralise one another. Precisely in the same way it may be seen that the endways pressures on $\mathrm{BC}, \mathrm{C} \mathrm{D}, \mathrm{DE}$, exactly counteract those on G H, F G, E F ; and in precisely the same way it may be shown that in any combination whatever of enlargements and contractions, provided the sectional area and direction of the pipe at the two ends are the same, the total endways effect impressed on the pipe by the fluid flowing through it must be nil.

In the experiment $I$ am about to show you, the several propo-

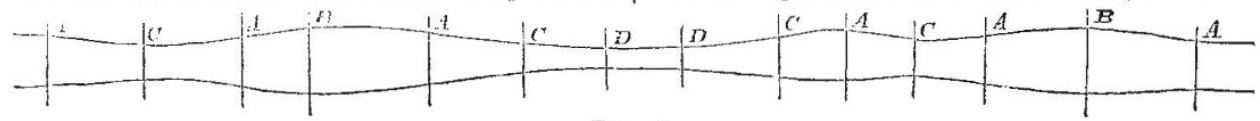

FIG. 18.

sitions which $I$ have been elucidating will be seen to be verified step by step, if due allowance be made for the effect of friction.

A cistern (see Fig. 20), in which a definite head of water is maintained, discharges itself through a continuous series of pipes, which in the local changes of diameter exhibit the several cha racteristic features which have been under consideration.

From $a$ to $b$ at the outlet end we have a contraction followed by an enlargement; from $e$ to $g$ the diameter is uniform, from

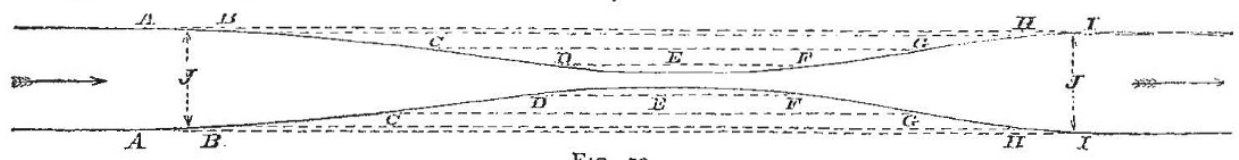

FIG. 19.

$h$ to $l$ we have an enlargement followed by a contraction. At the various critical features are fitted gauge-glasses such as have been described, so that the level at which the water stands in each indicates the pressure in the pipe at the point of attachment.
The series of pipes is laid out on an linclination which represents the mean resistance due to friction, or the "head" lost by friction, between the cistern and the outlet, in other words, the hydraulic mean gradient.

The mean diameter of the contracted part between $a$ and $b$

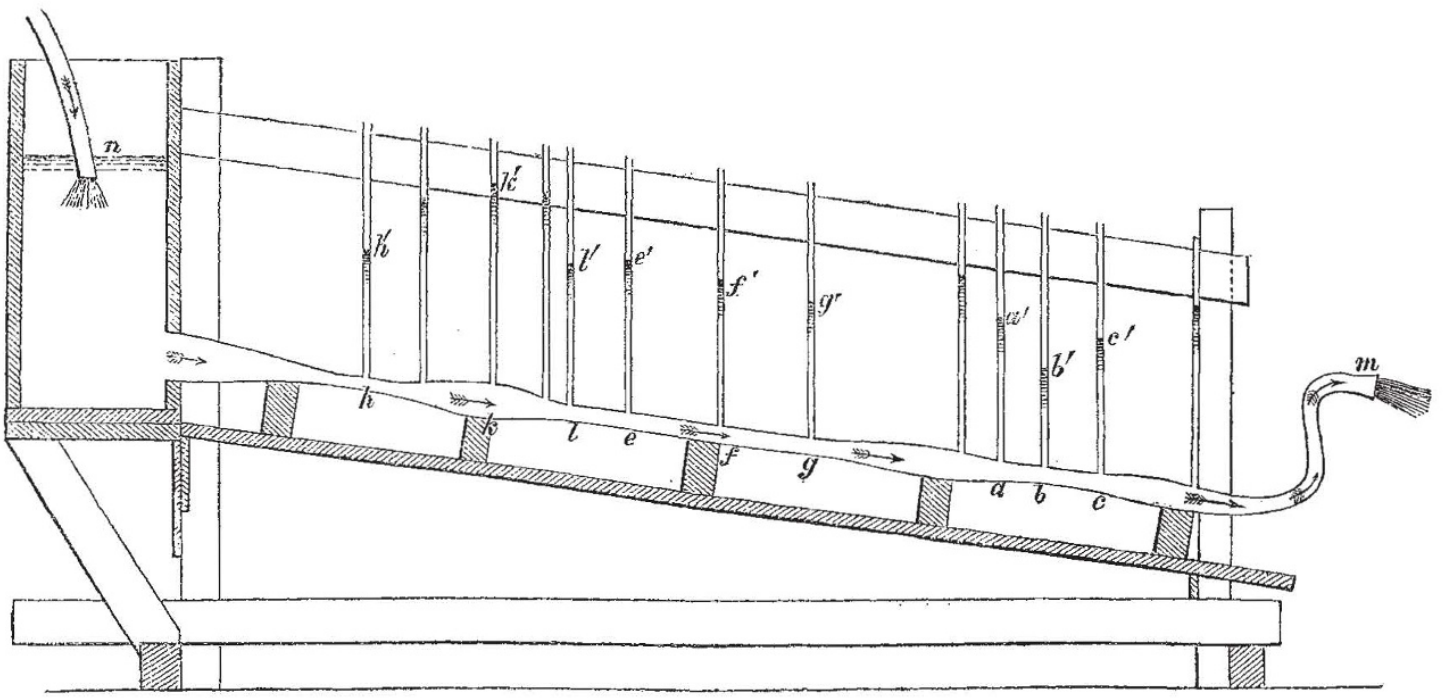

Fig. 20.

has been so determined by well-known hydraulic rules, that when | when examined in detail, they verify throughout the propositions it is compared with the adjoining harallel pipe, the hydraulic gradient shall be the same in each.

You observe that while the levels at which the water stands in the several gauge-glasses corresponds from end to end with the gradient from the head in the cistern to the head at the outlet; I have been establishing. Broadly speaking, where the diameter is smallest, the pressure falls most below the mean gradient; at the points where the diameters are equal, the pressures allowing for the gradient are equal, and what is a quantitative verifica tion, the gradient, or loss of head per foot between $a$ and $b$, 
as indicated by the gange-glass levels $a^{\prime}$ and $b^{\prime}$, is identical with that indicated by $\ell^{\prime} f^{\prime} g^{\prime}$, the gauge-glass levels connected with the parallel pipe.

In dealing with pipes of varying sectional area $I$ have hitherto treated only of the modifications caused in the forward motion of the particles of fluid; for I have limiled the argument to cases where the alteration in sectional area of the pipe is so gradual that, practically, the only alteration in the motion of the particles is that in their forward velocity; but I have previously shown that tortuosity in a pipe of uniform diameter does not introduce endways pressure, provided the initial and terminal directions are the same ; and it is easy to see that an elongated system of such gradually tapered pipes as we have been considering, may be also tortuous without introducing end ways pressure. Now tortuosity of flow is but another word for sideways deviation of flow.

This leads us up to the case of more sudden contractions or enlargements in pipes, where the particles next the sides of the pipes have to follow their surfaces and must therefore be moved rapidly sideways in their course.

We will, for simplicity, consider the case of a contraction (see Fig. 2I), and one in which the pipe resumes the same diameter beyond the contraction.

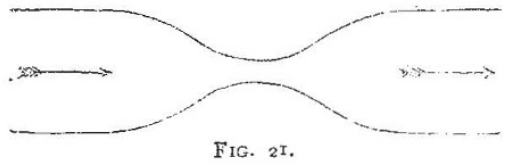

The particles along the central line pursue a straight course, and are subject only to the changes of pressure necessary to induce the changes of velocity.

To consider the behaviour of the other particles, let us assume that we insert a number of perfectly thin partitions (see Fig, 22), which we lay in such a manner that they exactly follow the paths of the particles of flu d at each point, so as not in any way to affect their motion; these partitions are quite imaginary, and merely assist us in looking upon the entire fluid in question as divired into a number of small streams. These streams are generally curvilinear, and vary in sectional area; and at the point beyind the contraction where the pipe resumes its former sectional area, we shall naturally find these minor streams occupying the same sectional area as Eefore, and moving with the same velocity as before.

Now each of these smail streans is exactly represented by a stream of fluid flowing within a pipe, that pipe being curvilinear and gradually varying in sectional area, and its two ends being of the same sectional area and in the same straight line. We have seen that in the case of such a stream, the sum total of all the forces due to its motion has no resultant longitudinally; and this will be equaliy the case, whether the envelope of the stream

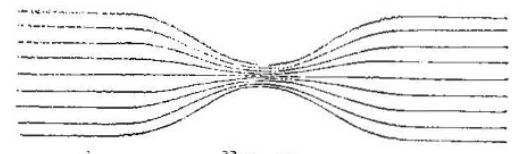

F1G. 22.

be an actual pipe or the mutual pressure of adjacent streams; this envelope will not be moved endways by the flow of the fluid. What is true of each stream is true of all put together; and thus it follows that the whole body of fluid which these separate streams constitute does not exert any endways force ; or, in other words, there will be equilibrium of fluid forces throughout the passage of the fluid through a local contraction in a pipe such as ve have been considering. The same line of argument evidently holds gocd in the case of an enlargement, where the pipe beyond the enlargement regains the same diameter as before.

In illustration of the conclusions which have been thus far established, if we had a perfect fluid with which to try the experiment, we might exhibit a very instructive and striking result.

Assume a ferfect stream of fluid flowing through a pipe of very large diameter, $\mathrm{ABC}$, with a contraction in it at $\mathrm{B}$, as shown in Fig. 23, and that the equal pressures at $A$ and $C$ on either side of the contraction are indicated by the head of fluid in pressure-gauges $\mathrm{A} D, \mathrm{CE}$-the pressure at $\mathrm{B}$, which will be less, being represented by the height BF. Now, the cendition of the pipe at $A$ will be just the same if we suppose the pipe supplied from a large cistern $G$, as shown in Fig. 24; and the appropriate pressure at $\mathrm{A}$ will be maintained, if the fluid stands in the cistern $\mathrm{G}$ at a height $\mathrm{H}$, equal to the head $\mathrm{AD}$ in the pressure-gauge. So, again, the condition of the pipe at $\mathrm{C}$ will be the same if the pipe discharges into a cistern, $I$; and the appropriate pressure at $\mathrm{C}$ will be maintained, and can only be

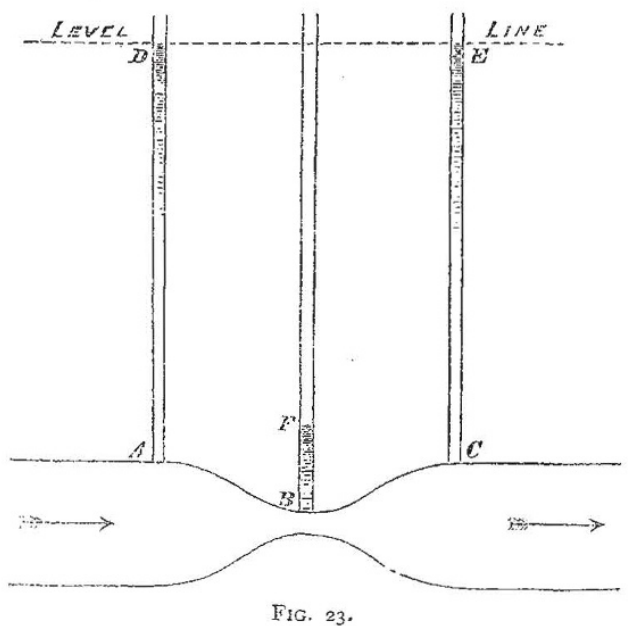

mainlained, if the water in the cistern stands at a height $J$, equal to the head $\mathrm{CE}$ in the pressure-gange, which is, in fact, the same level as $H$ in the cistern $G$; so that if we once establish the motion through the pipe $\mathrm{ABC}$, and maintain the supply of fluid, we shall have the fluid running rapidiy, and continuing to run with unabated rapidity, from one cistern into another, though both are at the same head.

If we take such a condition of things that the pressure at $B$ is zero, or, in other words, if the velocity at $B$ is that due to the head $A D$, then we might cat the pipe at $B$ and separate the two cisterns as shown in Fig. 25, and we should find the fluid issuing at $\mathrm{B}$ in a jet, and re-entering the pipe again at $\mathrm{K}$, and rising as before in the cistern $I$ to the same level with a perpetual flow.

The experiment here suggested is, if rightiy understood, only a specialised instance of the properties of what in the previous experiment was termed a contraction followed by an enlargement; it is in fact as if in that experiment the diameter of the contracted part had been so far reduced that the pressure within it would have sunk apparently to zero, that is to say, in reality to the pressure of the atmosphere; in that case, of course, the pipe which enclosed that portion of the stream would have become simply an irert envelope, and might have been removed without affecting the dynamic properties of the stream. Theore. tically indeed with the frictionless fluid the contraction of jet might be carried so far as not merely to obliterate all positive pressure, but to produce a negative pressure equal to that of the

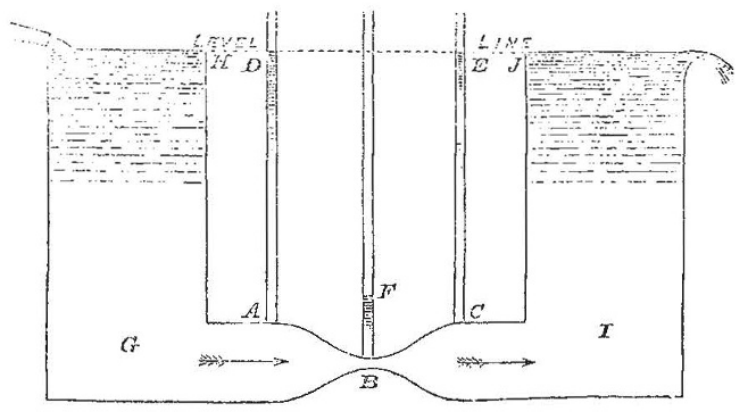

atmosphere. For in fact the conditions thus brought into opera. tion would be in effect identical with those which would exist were the experiment performed in vacuo, and the head in cistern and at the outlet were both increased by 34 feet ; but the theo. retical possibility thus indicated is greatly curtailed by friction, and the illustrative experıment $I$ am about to exhibit deals only with the case in which the pressure at the contraction is reduced 
apparently to zero, or in reality as I have said to that of the atmosphere.

In the apparatus as here arranged, consisting of the discharging and the recipient cistern, with the intervening jet-orifice and recipient-orifice, the overflow of the recipient cistern is at 18 inches above the centre of the orifices.

As I continue to fill the discharge cistern, you observe the jet shoots across the open space between the orifices, and the waterlevel continues to rise in the recipient cistern; and so long as the head in the former is maintained at a moderate height above that in the latter, the whole of the stream enters the recipient orifice, and there is no waste except the small sprinkling which is occasioned by inexactness of aim, and by the want of exact circularity in the orifices.

When the head in the recipient has reached the overflow, and thus remains at a steady height of 18 inches above the orifices, the complete reception is insured by maintaining a head of $20 \frac{1}{2}$ inches in the discharging cistern, or an excess of head of $2 \frac{1}{2}$ inches on the discharge side; and this excess, in effect, represents the energy wasted in friction.

You observe that as I diminish the supply of water and allow the excess of head in the discharger to become reduced, a steadily increasing waste becomes established between the orifices; and it is interesting to trace exactly the manner in which the friction operates to produce this result.

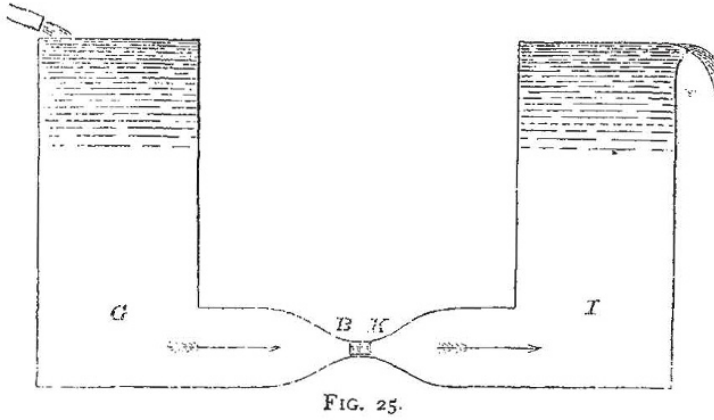

If the conoids of discharge and reception are tolerably short as they are here, it is the outer annule or envelopes of the stream which are in the first instance aflected, that is to say retarded, by friction, and the escape or waste between the orifices implies that this surface-retardation has reduced the velocity of those envelopes below that due to the head in the recipient; thus an annular counter-current is able to establish itself, and in fact constitutes a counter discharge from the recipient.

As the quantity of water which actually enters the recipient, or in other words the speed of the inflow, is reduced, the friction which belongs to that part of the stream is reduced also, but that which belongs to the issuing jet is unabated, and this circumstance virtually magnifies the waste; it is probable, how ever, that to the last the velocity of the central zones of the jet remains equal to that due to the head in the discharger, and hence you will observe that unless this is reduced below the level of the overflow, the head in the recipient is fully maintained to that level, though the whole quantity discharged is wasted between the orifices.

When the supply is altogether cut off, both cisterns simul taneously empty themselves, the two jets meeting between the orifices, and becoming spread into a beautiful plane disc or film of water at right-angles to the line of discharge; but you will notice that from some inequality in the commencement of the action, and to some extent probably from a quasi-instability in the equilibrium of the double discharge, one of the jets will presently for a moment get the better of the other and drive it back so as almost to arrest its flow, and thus for the moment arrest also the waste of head on that side; but the momentary excess of head thus occasioned almost instantly asserts its superiority, producing a jet of superior force, and thus driving back for a moment the opponent by which it bad just before been mastered. Thus a curious oscillation of discharge ensues, which is to a large extent a true dynamic phenomenon somewhat analogous to that which becomes established in an inverted syphon partly filled with water, if for a moment the head is increased in one of the legs; the reaction which in the syphon is furnished by its continuing through the bend, is, in the case before you, furnished by the dynamic reaction of the jets, but the circumstances here involve an instability which does not exist there, so that the small initial disturbance presently magnifies itself into one of considerably greater range.

This curious corollary phenomenon of the alternated retardation of discharge, though not strictly relevant to the main object of the experiment, is nevertheless highly interesting in itself and tends to enlarge our apprehension of some of the characteristic features of fluid dynamics.

(To be continued.)

NOTES

TUESDAX being St. Andrew's Day, the anniversary meeting of the Royal Society, as required by their charter, was held. The President, Dr. Hooker, began his address with a few remarks on the large number of eminent Fellows whose names appeared in the death-list of the past year, and then gave a summary of the numerous measures for "the improvement of natural knowledge" undertaken by the Society. These com. prise the publication of papers in the "Philosophical Transactions," in a separate form; preparation of additional volumes of the catalogue of scientific papers ; the labours of committees in connection with the Transit of Venus Expedition, and the researches of naturalists in Kerguelen and Rodrigues; the Eclipse of the Sun Expedition to Siam, the Polar Expedition, the voyage of the Challenger, and of the Committees appointed to consider the suggested modification of the regulations under which candidates are elected into the Society. The auditors' report showed that the pecuniary resources of the Society were in a satisfactory condition, and Dr. Hooker mentioned the bequests made to the Society by the late Sir C. Wheatstone and Mr. H. Dircks. The medals were then presented, the Copley medal to Dr. Hofmann, a Royal medal to Mr. Crookes, and a Royal medal to Dr. Oldham (at present in India), through Prof. Ramsay. The proceedings terminated with the election of council and officers (comprising the list of names already published) for the ensuing year. We hope to refer at length next week to the President's address. The anniversary dinner was held at Willis's Rooms, Dr. Hooker in the chair, supported by the Marquis of Salisbury, Lord Cardwell, Mr. W. H. Smith (of the Treasury), the Right Hon. Robert Lowe, Mr. Farrer, Admiral R. Hall, Mr. Lyon Playfair, Dr. Hofmann, Mr. Crookes, and a large number of the Fellows of the Society and their friends.

ON Monday night there was a pleasant and lively meeting at the Royal Geographical Society, over Mr. Stanley's work on the Victoria Nyanza. The paper read was by Col. Grant, C.B., the old companion of Speke, and he awarded hearty praise to Stanley, whose work he estimated as of high geographical importance. At the same time he showed that Stanley's discoveries seemed to confirm the discoveries of Speke as far as these went. The former estimates the circumference of the lake at 890 geographical miles, which coincides essentially with Speke's estimates. Sir Samuel Baker spoke much to the same effect as Col. Grant, both as regards Stanley and Speke, as did also Capt. Burton, while Mr. Edwin Arnold acted the part of Stanley's representative. It was announced that the Church Missionary Society are to take advantage of King Mtesa's invitation to send out missionaries ; Sir Samuel Baker believes that the good Mtesa mistook Stanley for Livingstone, whom he had been informed might be expected from the south. Sir $\mathrm{H}$. Rawlinson read some extracts from Col. Gordon's letter on the Albert Nyanza, which he trusted would also be explored by Mr. Stanley.

Thr Queen has conferred upon Dr. W. B. Carpenter, F.R.S., the honour of the Companionship of the Civil Division of the Order of the Bath.

THE Royal Academy of Sciences of Berlin has elected Dr. Frankland and Prof. A. W. Williamson, of London, corresponding members of the section of Physics and Mathematics. 